\title{
NOTE
}

\section{Comparison of oceanic turbulence and copepod swimming}

\author{
Hidekatsu Yamazaki***, Kyle D. Squires *** \\ Department of Ocean Sciences, Tokyo University of Fisheries, 4-5-7 Konan, Minato-ku, Tokyo 108, Japan
}

\begin{abstract}
There is a large number of phenomena which determine zooplankton motion in the upper ocean. This note compares the swimming speeds of a representative sample of zooplankton (Euchaeta rimana, Oithona davisae, and Metridia pacifica) with turbulent velocity fluctuations in the upper ocean. It is shown that nominal swimming speeds of these zooplankton are larger than velocity fluctuations in the seasonal thermocline. Consequently, organism motion can be independent of the local turbulent flow field in this region.
\end{abstract}

KEY WORDS: Turbulence - Dissipation - Copepod swimming

Copepods are the most dominant crustaceans and comprise at least $70 \%$ of mesozooplankton fauna (Lalli $\&$ Parsons 1993). The common perception of zooplankton transport in the ocean is that they drift with the ambient fluid motion, hence these organisms are coined 'plankton'. The general impression is thus that zooplankton drift with the ambient flow. Indeed, in oceanic currents such as the Gulf Stream and the Kuroshio Current, bulk transport is entirely due to these currents and zooplankters do not directly sense transport on such large scales. At the individual level, however, the local turbulent flow field is quite relevant to daily life. Flows at scales less than about $1 \mathrm{~m}$ are of considerable interest for a typical zooplankton having a size of the order $1 \mathrm{~mm}$. At these scales of motion one of the main factors shaping their environment is plankton swimming ability. Plankton with swimming speeds substantially higher than turbulent velocity fluctuations can be expected to exhibit motion independent of

-E-mail: hide@aquarius.tokyo-u-fish.ac.jp

Present addresses:

" School of Earth and Ocean Sciences, University of Victoria, Victoria, B.C., Canada V8W 2 Y2

... Department of Mechanical Engineering, University of Vermont, Burlington, Vermont 05405-0156, USA the surrounding flow, while the motion of plankton having lower swimming speeds than turbulence should be dictated almost entirely by the local flow.

During calm weather conditions the ambient fluid motion for an individual plankter may be laminar. On the other hand, stormy conditions can produce extremely high turbulence near the surface. Regardless of the strength of turbulence at the sea surface, the intensity diminishes significantly with depth (Oakey 1985, Yamazaki \& Osborn 1988). For example, during windy conditions the intensity of turbulence beneath the sea surface has been reported in the range $10^{-5}$ to $10^{-4} \mathrm{~W} \mathrm{~kg}^{-1}$ (as measured by the kinetic energy dissipation rate) and decreases to roughly $10^{-6} \mathrm{~W} \mathrm{~kg}^{-1}$ within $10 \mathrm{~m}$ depth (Yamazaki \& Kamykowski 1991, Osborn et al. 1992). Although this is a considerable reduction in the dissipation rate compared with surface values, it is still highly turbulent in comparison with the minimum reported values of $10^{-10} \mathrm{~W} \mathrm{~kg}^{-1}$, which is considered to be a background nonturbulent value (Moum \& Lueck 1985). Hence, a single plankter may experience changes in the dissipation rate varying over 6 orders of magnitude.

To compare velocity fluctuations at scales relevant to plankton motion with the swimming ability of an organism, an objective method for computing the turbulent velocity fluctuation from a continuous spectrum is required. We adopt an empirical definition based on the Ozmidov scale which has been widely accepted by the physical oceanography community (e.g. see Gargett et al. 1984, Yamazaki 1990, Seim \& Greg 1994). The Ozmidov scale, $L_{0}$, is a measure of the length at which turbulence inertial forces are balanced by the buoyancy force arising from a background stratification and is defined in terms of the dissipation rate $\varepsilon$ and buoyancy frequency $N$, i.e. $L_{0}=\left(\varepsilon / N^{3}\right)^{1 / 2}$. Since the minimum eddy size in turbulence is proportional to the Kolomogorov scale, $L_{k}=\left(v^{3} / \varepsilon\right)^{1 / 4}$, where $v$ is the kine- 

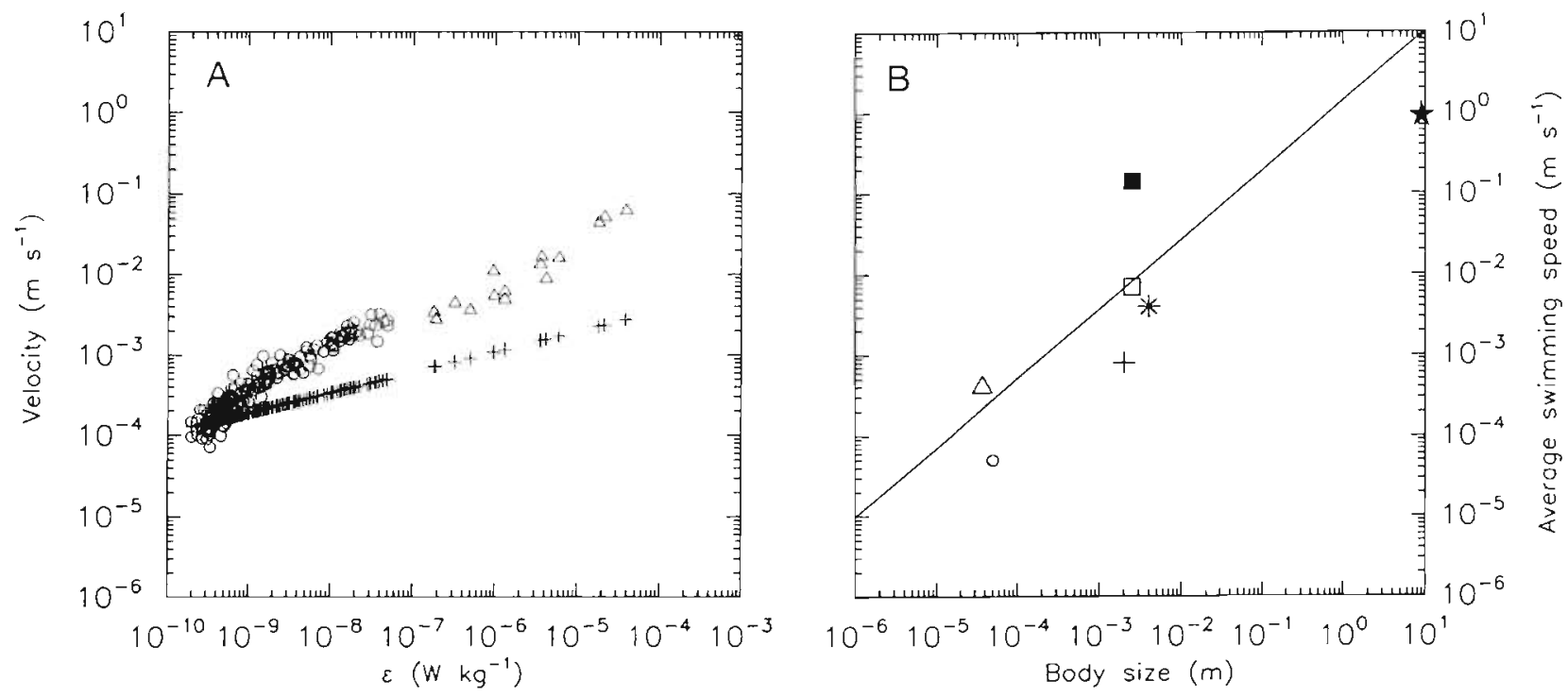

Fig. 1. (A) Kolmogorov velocity scale (+) and the rms turbulent velocity scale against observed dissipation rates ( $\varepsilon$ ). (O) Samples from a seasonal thermocline (Yamazaki 1990); ( $\Delta$ ) those from turbulence observed in a fjord (Gargett et al. 1984). (B) Average swimming speed of various organisms against body size. Shown are 2 phytoplankton ( $\triangle$, Gyrodinium dorsum; o, diatom), 3 zooplankton ( $\square$, Euchaeta rimana; + , Oithona davisae; $*$. Metridia pacifica) and $\star$, a shark. Empirical relationship between the body size and the nominal swimming speed suggested by Okubo (1987) shown by solid line. (西) Escaping swimming speed for E. rimana (Yen 1988)

matic viscosity, we integrated measured turbulent velocity spectra between $L_{k}$ and $2 L_{0}$ in order to estimate the rms turbulent velocity. For a typical turbulent patch in a seasonal thermocline, with $\varepsilon=10^{-8} \mathrm{~W} \mathrm{~kg}^{-1}$ and $N=0.01 \mathrm{~s}^{-1}$, the Ozmidov length $2 L_{0}$ is $20 \mathrm{~cm}$ and the Kolmogorov lengthscale $L_{\mathrm{k}}$ is $0.32 \mathrm{~cm}$. Fig. $1 \mathrm{~A}$ shows observed rms turbulence velocities and the associated dissipation rates. Also shown is the Kolmogorov velocity, $v_{k}$, which is a measure of the minimum velocity scale of turbulence and is defined as $v_{k}=$ $(v \varepsilon)^{1 / 4}$.

One measure of the extent to which plankton motion is independent of the local flow is the swimming ability of the organism relative to local turbulent velocity fluctuations. Organisms with swimming speeds higher than turbulent velocities can be expected to move independently of the local flow. Fig. 1B shows the nominal swimming speeds of a representative sample of phytoplankton and zooplankton. The swimming speed of sharks has also been shown for comparison (Okubo 1987). Three different species of zooplankton, Euchaeta rimana, Oithona davisae, and Metridia pacifica, are presented in Fig. 1B. A $50 \mu \mathrm{m}$ diatom, which is a representative size for living diatoms, sinks at $5 \mathrm{~m} \mathrm{~d}^{-1}$ (Lalli \& Parsons 1993) Another phytoplankton depicted in this figure is Gyrodinuim dorsum, which can swim upward at about $30 \mathrm{~m} \mathrm{~d}^{-1}$ (Kamykowski et al. 1992). It is clear from Fig. 1A that turbulent velocities in the wind-induced mixing layer and seasonal thermocline are substantially higher than phytoplankton swimming speeds and therefore it is not possible for dinoflagellates to move independently of the local flow.

Comparison of Figs. 1A \& B shows that zooplankton motion can in fact be independent of the ambient turbulent flow. According to Yen (1988), Euchaeta rimana can accelerate up to $8.9 \mathrm{~cm} \mathrm{~s}^{-1}$ for burst swimming and has a nominal swimming speed of roughly $7 \mathrm{~mm} \mathrm{~s}^{-1}$ Oithona davisae is smaller than E. rimana, and is a rather weak swimmer with nominal swimming speed about $0.8 \mathrm{~mm} \mathrm{~s}^{-1}$ (Uchima \& Hirano 1988). Metridia pacifica is classified as a large-size copepod, about $4 \mathrm{~mm}$ in length, and its nominal swimming speed is roughly $4 \mathrm{~mm} \mathrm{~s}^{-1}$ (Wong 1988 ). In the seasonal thermocline, the dissipation rate in the water column is in the range $10^{-10}$ to $10^{-8} \mathrm{~W} \mathrm{~kg}^{-1}$ and rms turbulent velocity fluctuations are no more than $1 \mathrm{~mm} \mathrm{~s}^{-1}$ (cf. Fig. 1A). Therefore, even a weak swimmer such as $O$. davisae has a swirnming speed comparable to the turbulent velocities in this region. Thus, while zooplankton motion in highly energetic flows, e.g. tidal flows and upper ocean mixing layers, is dictated by the external flow field, copepod swimming speeds in the seasonal thermocline are higher than turbulent fluctuations and therefore organism motion can be independent of the local flow field in this region.

Although the focus of this note has been on the Ims turbulent velocity scale relative to the swimming ability of plankton, it is also important to mention that in addition to the variable translational velocity added by turbulence, there will also be a rotational torque due to the local shear around the plankter (e.g. Kessler 1986. 
Bowen et al. 1993). The interaction between turbulent shear and rotation of a plankter is an effect which complicates independent organism motion. Turbulent shear may interfere with various behavioral responses as well as mechanoperception of prey by predators, for example. Furthermore, stretch receptors monitoring the deformation of a body denser than the ambient fluid have been hypothesized to give a plankter information about the direction of gravity (Machemer \& Bräucker 1992). The local shear around a copepod may affect stretch receptors in such a way as to interfere with their perceived gravitaxis, as well as directed swimming. The study of local velocity strain effects on plankton behaviour is an important area of future research.

Finally, it is also important to note that 2 effects on plankton ecology not considered here are the intermittency of the dissipation rate and the coherent nature of the small scales of turbulence (see e.g. Yamazaki \& Lueck 1990, Yamazaki 1993 for further discussion). These features also comprise areas of important future research.

Acknowledgements. We appreciate helpful comments on the manuscript by L. Haury, M. Omori, C. Davis, S. Gallager, and conscientious anonymous referees. This work was supported by NSF grant OCE-9409073. ONR grant N00014-92-1653 and Tokyo University of Fisheries 100 year anniversary grant

\section{LITERATURE CITED}

Bowen JD, Stolzenbach KD, Chisholm SW (1993) Simulating bacterial clustering around phytoplankton cells in a turbulent ocean. Limnol Oceanogr 38(1):36-51

Gargett AE, Osborn TR, Nasmyth PW (1984) Local isotropy and the decay of turbulence in a stratified fluid. J Fluid Mech 144:231-280

Kamykowski D, Reed R, Kirkpatrick GJ (1992) A comparison of sinking velocity, swimming velocity, rotation, and path

This note was presented by T. Kiorboe (Senior Editorial Advisor), Charlottenlund, Denmark characteristics among six marine dinoflagellate species Mar Biol 113:319-328

Kessler JO (1986) The external dynamics of swimming micraorganisms. Prog Phycol Res 4:258-305

Lalli CM, Parsons TR (1993) Biological oceanography: an introduction. Pergamon Press, Oxford

Machemer H, Braucker R (1992) Gravireception and graviresponses in ciliates. Acta Protozool 31(4):185-214

Moum JN, Lueck RG (1985) Causes and implication of noise in oceanic dissipation measurements. Deep Sea Res 32: $379-390$

Oakey NS (1985) Statistics of mixing parameters in the upper ocean during JASIN phase 2. J Phys Oceanogr 15: $1662-1675$

Okubo A (1987) The fantastic voyage into the deep: marine biofluid mechanics. In: Teramoto E, Yamaguchi M (eds) Mathematical topics in population biology, morphogenesis, and neurosciences. Biomathematics Vol 71, SpringerVerlag, Berlin, p 32-47

Osborn T, Farmer DM, Vagle S, Thorpe SA, Cure M (1992) Measurements of bubble plumes and turbulence from a submarine. Atmos-Ocean 30:419-440

Seim HE, Greg MC (1994) Detailed observation of a naturally occurring shear instability. J Geophys Res 99:10049-10073

Uchima M, Hirano R (1988) Swimming behavior of the marine copepod Oithona davisae: internal control and search for environment. Mar Biol 99:47-56

Wong CK (1988) The swimming behavior of the copepod Metridia pacifica. J Plankton Res 10:1285-1290

Yamazaki H (1990) Stratified turbulence near a critical dissipation rate. J Phys Oceanogr 201:583-1598

Yamazaki H (1993) Lagrangian study of planktonic organisms: perspectives. Bull Mar Sci 53:265-278

Yamazaki H, Kamykowski D (1988) The vertical trajectories of motile phytoplankton in a wind-mixed water column Deep Sea Res 38:219-241

Yamazaki H, Lueck R (1990) Why oceanic dissipations are not lognormal. J Phys Oceanogr 20:1907-1918

Yamazaki H, Osborn TR (1988) Review of oceanic turbulence implication for biodynamics. In: Rothschild BJ (ed) Toward a theory on biological-physical interactions in the world ocean. Kluwer Academic Publishers, Dordrecht, p $215-233$

Yen J (1988) Directionality and swimming speeds in predatorprey and male-female interactions of Euchaeta rimana, a subtropical marine copepod. Bull Mar Sci 43:395-403

Manuscript first received: February 8, 1996

Revised version accepted: August 23, 1996 